\title{
Effluent recirculation enables near-complete oxidation of organics during supercritical water oxidation at mild conditions: A proof of principle
}

\author{
Dongdong Zhang ${ }^{\mathrm{a}, \mathrm{b}}$, Stef Ghysels ${ }^{\mathrm{b}}$, Frederik Ronsse ${ }^{\mathrm{b}, *}$ \\ a Institute of Urban Agriculture, Chinese Academy of Agricultural Sciences, Chengdu, China \\ ${ }^{\mathrm{b}}$ Thermochemical Conversion of Biomass Research Group, Ghent University, Coupure Links 653, 9000, Ghent, Belgium
}

\section{H I G H L I G H T S}

- Supercritical water oxidation (SCWO) was performed at mild conditions.

- Effluent recirculation was applied to improve organic oxidation efficiency.

- The oxidizing capacity and oxygen consumption were favorable for recirculation.

- A single and small setup at constant conditions oxidized different organics.

\section{A R T I C L E I N F O}

\section{Article history:}

Received 24 October 2019

Received in revised form

2 February 2020

Accepted 13 February 2020

Available online 18 February 2020

Handling Editor: Jun Huang

\section{Keywords:}

SCWO

Mild conditions

Effluent recirculation

Organic waste

\begin{abstract}
A B S T R A C T
This work presents a continuous set-up for SCWO, which was operated at mild conditions ( $380{ }^{\circ} \mathrm{C}$, $25 \mathrm{MPa}$, oxidant equivalence ratio of 2.0 and residence time of $26 \mathrm{~s}$ ) to oxidize cellulose, lignin, and acetic acid as model compounds. The aim was to oxidize different organics consecutively to near completion in the same mild reaction conditions and set-up. These conditions can overcome some drawbacks associated to SCWO. To combine near complete oxidation with the applied mild process conditions, aqueous effluent from SCWO, containing intermediates from incomplete oxidation, was recycled for consecutive oxidation. Meanwhile, fresh feedstock was continuously fed to retain the process capacity. Upon recycling the aqueous effluent three to four times, depending on the feedstock, the oxidation efficiency increased from $63.9 \%, 45.3 \%$ and $28.3 \%$ in a single pass for cellulose, lignin, and acetic acid, respectively, to near $100 \%$. The principle of effluent recirculation should allow a compact set-up to perform almost complete oxidation of different organics at mild conditions. The principles and effects of effluent recirculation are outlined, as well as practical consequences and perspectives of this novel principle to SCWO.
\end{abstract} (C) 2020 Elsevier Ltd. All rights reserved.

\section{Introduction}

Supercritical water oxidation is a technology that applies the unique solvent properties of supercritical water (critical point being $374{ }^{\circ} \mathrm{C}$ and $22.1 \mathrm{MPa}$ ) to establish the oxidation of organic compounds. Within the environment of supercritical water, reactants (being both the organics as well as the oxidizer) appear in a homogeneous single phase, boosting oxidation reaction rates dramatically. SCWO can fit within a waste management strategy to

\footnotetext{
* Corresponding author.

E-mail addresses: dongdongzhang.ac@outlook.com (D. Zhang),Frederik.ronsse@ ugent.be (F. Ronsse).
}

decompose harmful and/or high-risk substances (e.g., medical wastes), or high-moisture waste streams (e.g., sewage sludge) (Marrone, 2013; Brunner, 2014; Zhang et al., 2018, 2020).

\subsection{SCWO for waste management}

SCWO can mitigate hazardous organic wastes to neat gaseous products, i.e., carbon dioxide (Al-Duri et al., 2015). In the case of high-risk substances, SCWO avoids the emission of toxic and noxious intermediates, e.g., dioxins (Zou et al., 2013b), which would occur in the case of incineration. With regards to high-moisture organics, SCWO can overcome the energy requirements to dry the feedstock prior to its processing.

High-risk organics that have been treated through SCWO are 
e.g., phenol (Matsumura et al., 2000), aniline (Ma et al., 2012), quinazoline (Gong et al., 2016), quinoline (Angeles-Hernández et al., 2009), and acrylonitrile (Shin et al., 2009). High-moisture waste, liquid wastes and specific wastewaters of significance for treatment via SCWO comprise e.g., oil-based cutting fluids (Jimenez-Espadafor et al., 2011), landfill leachate (Wang et al., 2011; Gong et al., 2015), industrial and/or sewage sludge (Qian et al., 2019; Yang et al., 2019) (Zou et al., 2013a; Miller et al., 2015) and wastewater from the pharmaceutical or dyeing industry (Sögüt and Akgün, 2009; Mylapilli and Sivamohan, 2019).

\subsection{Challenges and needs for SCWO operation}

Significant research efforts within the field of SCWO are dedicated to the optimization of (i) the operation temperature and pressure (Fig. 1a), (ii) the oxidizer to carbon ratio (Fig. 1b), (iii) the residence time (Fig. 1c) and/or (iv) a combination of those (Fig. 1d), in order to push oxidation efficiencies of carbon dioxide towards 100\%. Nevertheless, SCWO for high-level oxidation to carbon dioxide typically goes in tandem with severe disadvantages, associated with the applied operating conditions, always exceeding the critical point (Cocero et al., 2000; Chen et al., 2015; Gong et al., 2016).

While the oxidation efficiency of organic carbon increases if treated at reaction conditions far beyond the critical point (e.g., $500{ }^{\circ} \mathrm{C}-750{ }^{\circ} \mathrm{C}$ (Cocero et al., 2000)), corrosion of the reactor material becomes more severe (Fang, 2014; Tan et al., 2014). Moreover, high-temperature SCWO typically requires an auxiliary fuel, like methanol or ethanol (Shimoda et al., 2016; Zhang et al., 2019b), considerably increasing the operating costs (Fig. 1a). Higher oxidizer-to-organic-carbon ratios during SCWO also reach higher oxidation efficiencies as well as worse corrosion to the reactor. Oxidant equivalence ratio (OER) is defined as the ratio of applied oxygen over the stoichiometric amount required for complete oxidation of carbon. An OER between 0.5 and 1.0 does not reach high oxidation efficiencies due to the formation of solid products, probably caused by repolymerization reactions at low OER regimes. The formation of solids could inhibit organics from subsequent oxidation (Zhang et al., 2018). At OERs between 1.5 and 10.0, efficiencies close to $100 \%$ can be reached depending on other parameters, like the residence time (Pisharody et al., 1996; Zhang et al., 2013; Gong et al., 2016). The synergy of elevated operating temperatures and OERs enhances the oxidation of the recalcitrant intermediates, like acetic acid, formed during the SCWO of organic carbon (Meyer et al., 1995; Jin et al., 2001; Portela et al., 2001). However, increasing OER and temperature (Fig. 1b) causes more corrosion-related damage, and can lead in some cases to the evolution of $\mathrm{NO}_{\mathrm{x}}$ (Lousteau et al., 2017; Yang et al., 2017). Cocero et al. measured maximum $\mathrm{NO}_{\mathrm{x}}$ emissions of ca. $80 \mathrm{mg} / \mathrm{Nm}^{3}$ (operated at $750{ }^{\circ} \mathrm{C}$, residence time of ca. $40 \mathrm{~s}$ and OER of 1.8 ) (Cocero et al., 2000). The application of a catalyst could help to reduce the operating temperature, hence less corrosion, but like catalytic wet air oxidation, goes in tandem with additional costs.

Prolonging the residence time of the organic carbon (Fig. 1c-d) under mild SCWO conditions has therefore been investigated to reach efficient oxidation to carbon dioxide, while reducing stress and corrosion in the reactor and reducing $\mathrm{NO}_{\mathrm{x}}$ formation (Bermejo and Cocero, 2006; Guo et al., 2010; Fang, 2014; Al-Duri and Alsoqyani, 2017; Zhang et al., 2019a). This approach, albeit effective, gives rise to additional technical requirements, such as an increased reactor size and an associated increase of oxidizer injection points distributed over the reactor. These are considered as disadvantages: larger reactors require extra investment costs and bring more risks, while multiple oxidant injection points would make the setup more complex and more vulnerable.

\subsection{The principle and hypothesis of effluent recirculation for SCWO}

This work, therefore, investigated a new principle to SCWO (Fig. 1e), in which SCWO was performed at mild temperature and OER (the multiple SCWO boxes in Fig. 1 e were to simulate recirculation, only one reactor was used for the principle). In compensation, the residence time of organic carbon was prolonged by recycling the aqueous effluent, containing intermediates from incomplete oxidation. As a result, a SCWO process with effluent recirculation was proposed as in Fig. $1 \mathrm{f}$. The intermediates containing aqueous effluent entered the reactor along with fresh feed and oxidizer. The fresh feedstock and oxidizer flow remained constant. A detailed description of the set-up and recirculation procedure is outlined in Section 2.

Fig. $1 \mathrm{f}$ shows that the aqueous effluent from the reactor would always contain carbon from intermediate/refractory compounds. Indeed, it was anticipated that the residence time associated with a single pass in a small SCWO reactor was insufficient to reach $100 \%$

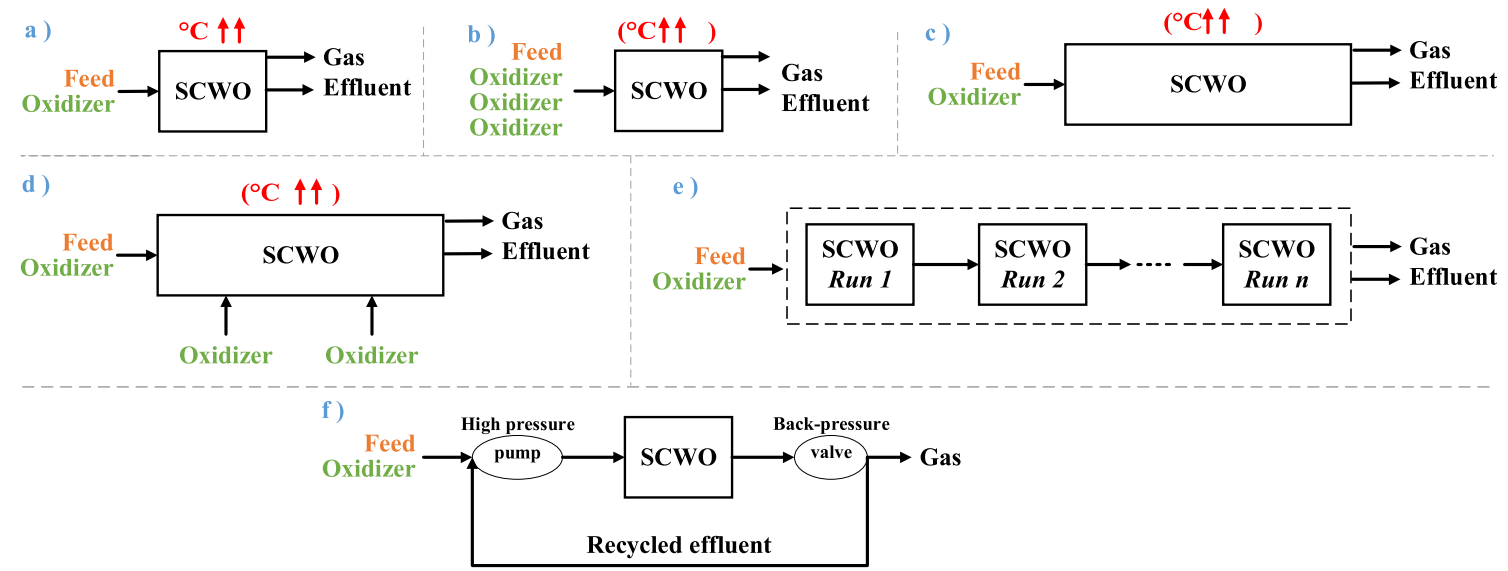

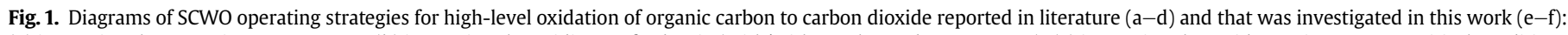

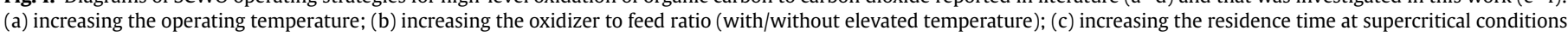

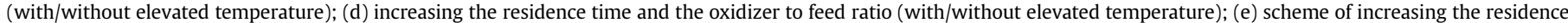

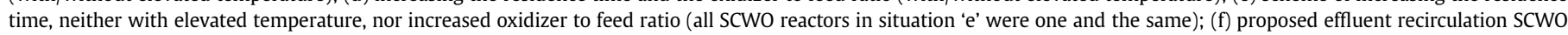
process. 
oxidation under mild conditions. Nevertheless, the principle of effluent recirculation during SCWO thus not pursues the complete oxidation of feedstock at one time. Instead, it rather illustrates an alternative paradigm for SCWO, where gradual oxidation of organics upon each recirculation of the effluent at mild reaction conditions is the main concern. Carbon in the liquid phase leaves the SCWO system only in the gas phase (e.g., $\left.\mathrm{CO}_{2}\right)$, which is the final product. It is particularly important to mention that fresh feed is constantly fed all the time in this new principle. Therefore, the new principle only loses process capacity to a limited extent. Moreover, the loss in process capacity is controllable.

As a consequence, the following benefits from the new principle were anticipated: i) the set-up does not have to be increased in size to accommodate larger residence times (stemming from recirculation); (ii) a smaller/compact reactor is possible to achieve the same oxidation efficiency as a conventional, single-pass SCWO, while would be less vulnerable to damage caused by high pressure and temperature; (iii) mild temperature and low OER minimize corrosion risks and enlarge reactor materials selection; (iv) one fixed setup, maintained at constant reaction conditions, could oxidize different organics due to gradual oxidation to final products. Their residence time is basically infinite as intermediates stay within the system. The principle of effluent recirculation is fairly common in chemical engineering practices, but has not yet been investigated for SCWO.

The proposed approach is only viable if organic carbon from a certain injection of fresh feed is completely oxidized upon a discrete number of SCWO passes (i.e., recirculation runs). Therefore, the fundamental hypothesis to be investigated was: (near) complete oxidation of freshly injected organic carbon is reached after a discrete number " $n$ " of SCWO runs, i.e., upon recycling $n-1$ times its residual intermediates in the effluent.

The hypothesis was investigated for cellulose and lignin being the two most abundant molecules in nature (Pisharody et al., 1996; Drews et al., 2000; Fedyaeva et al., 2019), and for acetic acid being a model compound for soluble recalcitrant intermediates (Mizuno et al., 2000; Cabeza et al., 2011). As a proof-of-principle, the hypothesis has been tested in this work in a semi-continuous manner, as to simulate the recirculation of effluent, and for the convenience in sample analysis. The employed methods can be easily extended to a continuous system which is also discussed within this work.

\section{Materials and methods}

\subsection{SCWO set-up and operation}

A coiled tubular continuous reactor was used to test the principle, as shown in Fig. S1 in supplementary materials. The system consists of a feed pump, an oxidizer pump, a feed pre-heater coil, an oxidizer pre-heater coil, a tubular reactor $(100 \mathrm{~mL})$ surrounded by electric heating jackets, a cooler, a separator and a back-pressure regulator (Tescom, 26-1762-26-S). All pressurized parts were made of stainless steel $316 \mathrm{~L}$ (OD: $6.35 \mathrm{~mm}$, ID: $3.05 \mathrm{~mm}$ ), except the pre-heaters, reactor and cooler were made of alloy 600 (OD: $6.35 \mathrm{~mm}$, ID: $3.09 \mathrm{~mm}$ ). The whole setup has a total volume of $1300 \mathrm{~mL}$. In the pre-heating section, the organic feed and oxidizer streams reached a temperature between $180^{\circ} \mathrm{C}$ and $200{ }^{\circ} \mathrm{C}$ before being mixed and subsequently entering the reaction section. The time spent by the feed and oxidizer mixture in the preheaters was 90-180 s for the feed stream and $90-120 \mathrm{~s}$ for the oxidizer stream, depending on the stream flow rate (Albrecht, 2006; Zhang et al., 2019a).

\subsection{SCWO operational procedures}

During start-up, pumps A and B (see notation in Fig. S1 in supplementary) pumped pure water with set-constant mass flow rates of $1.12 \mathrm{~g} / \mathrm{s}$ and $0.60 \mathrm{~g} / \mathrm{s}$, respectively. A backpressure regulator was used to control the system's pressure at $25 \mathrm{MPa}$, with an accuracy of $\pm 0.3 \mathrm{MPa}$. After the flow rates stabilized, the system was preheated to $380^{\circ} \mathrm{C}$ by electrical heaters, with an accuracy of $\pm 1^{\circ} \mathrm{C}$. If all parameters reached the setpoint and remained stable, pumps A and B were switched from water to "feed stream" and "oxidizer stream", respectively. The feed stream was prepared by mixing either cellulose, lignin or acetic acid (analytical reagent grade, Sigma-Aldrich Chemie GmbH, Germany) with water to a concentration of $0.78 w t \%$. A magnetic stirrer was used to keep the feed in the supply vessel homogeneous. Hydrogen peroxide (33 wt\%, VWR, Belgium) was applied as the oxidizer. Therefore, the stock solution was diluted with demineralized water to reach an OER of 2.0, based on the mass fraction of carbon in cellulose, lignin, and acetic acid. The prepared hydrogen peroxide concentration in the oxidizer stream to reach an OER of 2.0 was $7.22 w t \%$ for cellulose, $12.12 w t \%$ for lignin and $6.32 w t \%$ for acetic acid.

The final concentration of organics after mixing the feed stream with the oxidizer stream (i.e., prior to entering into the tubular reactor) was $0.51 w t \%$, being $0.78 w t \%$ times the dilution caused by mixing with the oxidizer stream: $1.12 \mathrm{~g} . \mathrm{s}^{-1} /\left(1.12{\mathrm{~g} . \mathrm{s}^{-1}+}^{-1}\right.$ 0.60 g. $\left.\mathrm{s}^{-1}\right)$. The residence time of the feed/oxidizer mixture was $26 \mathrm{~s}$ in the reactor. After $2000 \mathrm{~mL}$ effluent had left the SCWO system, the gas and aqueous effluent composition were considered stable and sampled for analyses. The latter was further collected and recycled.

\subsection{Aqueous effluent recirculation procedure}

In our experimental procedure (Fig. 2a), no solid products were observed in any cases. The aqueous effluent was supposed to contain all the undecomposed organics. In this work, aqueous effluent was collected from its previous run. Afterwards, the aqueous effluent was taken as a solvent to mix with fresh (pure) feedstock (cellulose, lignin, or acetic acid) to again a concentration of $0.78 w t \%$ of (suspended) fresh feedstock in the mixture (fresh feedstock + aqueous effluent, labeled as in Fig. 2a) as they were in the initial run. This is the feed stream (fresh feedstock + aqueous effluent) for a recirculation run. Identical OERs were applied with respect to the fresh feedstock's carbon concentration as the design criterion, albeit the effluent, containing intermediates, was expected to increase the total organic carbon content in the feed stream for a subsequent SCWO run. As a result, the fresh feedstock and the oxidizer loading in recirculation runs would be the same as the initial run. The only difference would be that the influent in the recirculation runs contained undecomposed intermediates.

It is important to note that the overall feed volume (fresh feedstock + aqueous effluent + oxidizer stream) entering the SCWO run was larger than the recycled aqueous effluent, due to oxidizer being an aqueous hydrogen peroxide solution, and (minor) production of chemical water from oxidation reactions. In many practical cases, the feedstock also will contain significant amounts of water. This brought two issues. Firstly, the undecomposed intermediates in the recycled aqueous effluent were "diluted" upon mixing with fresh feedstock and oxidizer stream prior to the reactor. The recycled intermediates in the subsequent run thus remained the same components but at a lower concentration. The lower concentration of the recycled intermediates would evolve less carbon in the gas phase, resulting in a lower carbon oxidation capacity, quantified through the ratio of evolved gas-carbon over feedstock-carbon. As the feedstock stream had a fixed flow, the 

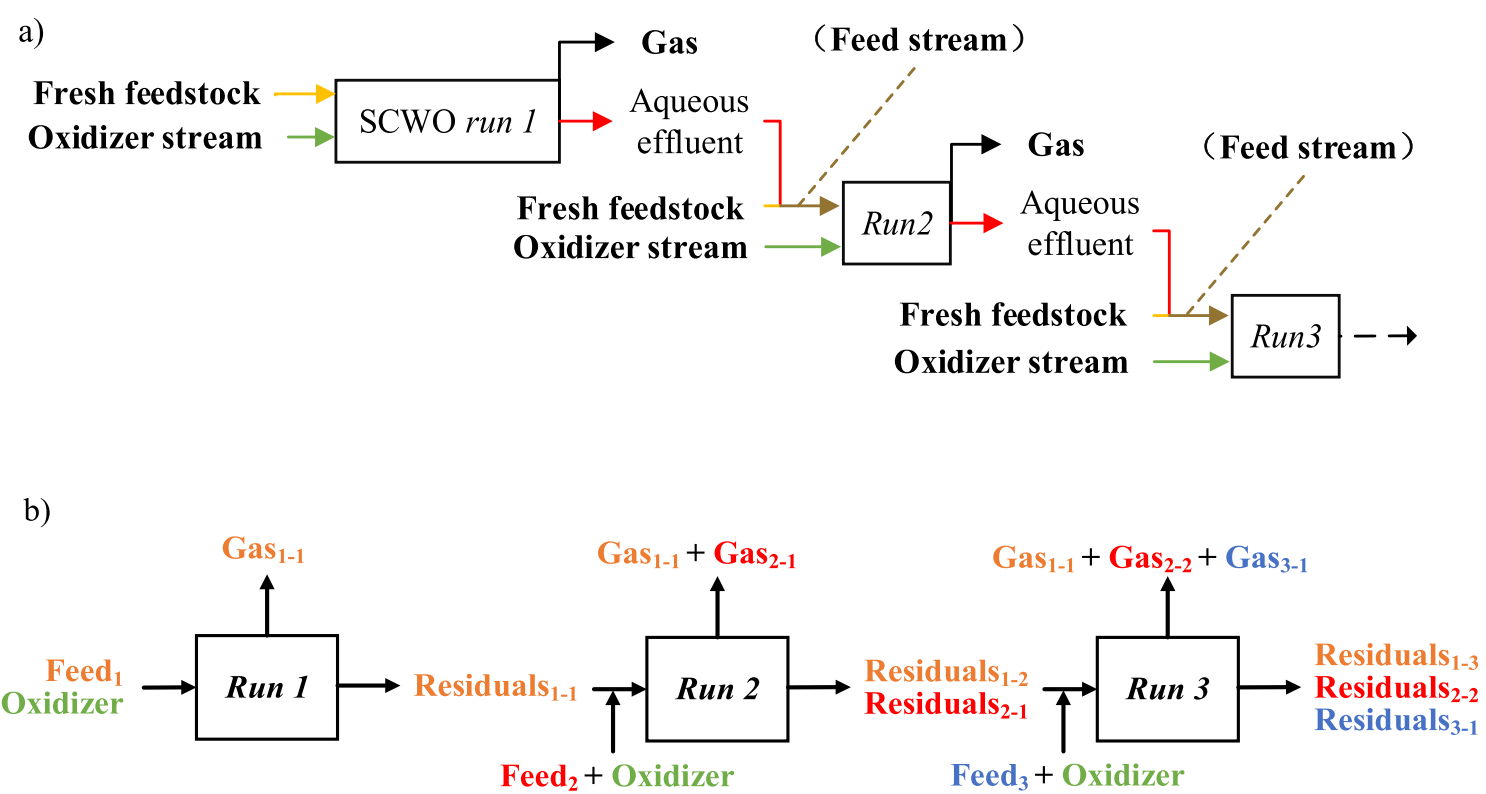

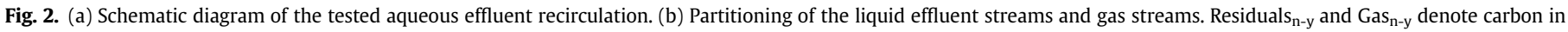
the liquid effluent and gas stemming from feed injected in the $n$th SCWO run upon $y$ SCWO runs.

dilution-induced decrease of the carbon oxidation capacity would obscure the evaluation of the changed oxidation efficiency upon effluent recirculation. Therefore, cumulative oxidation efficiencies (COE) were introduced in Section 2.4.6 to indicate the consecutive organic oxidation during multiple runs albeit multiple times diluted. Secondly, processing the aqueous effluent upon every recirculation runs would inevitably cause an ever-increasing liquid volume and then processing time. A concept was put forth in Section 3.4.1 to avoid the build-up of the aqueous effluent.

\subsection{Analytical techniques and calculations}

Carbon balances, yields, oxidation efficiencies, etc. were calculated, based on the carbon concentration of the incoming and outgoing streams to the SCWO system. The following sections describe the analyses and calculations to calculate residence time, carbon balances, oxidation efficiencies, etc.

\subsubsection{Residence time}

The residence time $\left(t_{R}\right.$, in $\left.\mathrm{s}\right)$ was calculated using:

$t_{R}=\frac{\rho_{R(P, T)} \times V_{R}}{\rho_{M} \times F_{M}}$.

where, $\rho_{\mathrm{R}(\mathrm{P}, \mathrm{T})}$ is the density $\left(\mathrm{kg} \cdot \mathrm{L}^{-1}\right)$ of the mixture at working temperature and pressure. $V_{R}$ is the reactor volume $(\mathrm{L}) ; \rho_{M}$ is the density of the mixture $\left(\mathrm{kg} . \mathrm{L}^{-1}\right)$ at atmospheric temperature and pressure (approximated by that of pure water) and $F_{M}$ is the flow rate of the mixture $\left(\right.$ L. $\left.\mathrm{s}^{-1}\right)$.

\subsubsection{Gas composition}

The composition of evolved gases was analyzed with a micro GC Varian 4900 equipped with two analytical columns. Column 1 is a $10 \mathrm{~m}$ Molesieve $5 \mathrm{~A}$ with backflush which is connected to a heated injector, and to a TCD detector using high purity He as carrier gas. Column 2 is a $10 \mathrm{~m}$ PPU column connected to a heated injector and to a TCD detector, using high purity He as carrier gas. The first column separated and quantified (vol\%) $\mathrm{H}_{2}, \mathrm{O}_{2}, \mathrm{~N}_{2}, \mathrm{CH}_{4}$ and $\mathrm{CO}$ (in order of occurrence of the peaks), whereas $\mathrm{CO}_{2}, \mathrm{C}_{2} \mathrm{H}_{4}, \mathrm{C}_{2} \mathrm{H}_{6}, \mathrm{C}_{3} \mathrm{H}_{6}$ and $\mathrm{C}_{3} \mathrm{H}_{8}$ were separated and quantified (vol\%) in the second column.

The run time in both columns was 240 s, with a sampling frequency of $100.0 \mathrm{~Hz}$. The injector temperature was $70^{\circ} \mathrm{C}$ for column 1 and $70{ }^{\circ} \mathrm{C}$ for column 2 . The oven temperature was $75{ }^{\circ} \mathrm{C}$ for column 1 and $70^{\circ} \mathrm{C}$ for column 2 . A static pressure was established of $150.0 \mathrm{kPa}$ for both columns. The stabilization time before measurement was $2 \mathrm{~s}$, while the sampling time was $30 \mathrm{~s}$. The sample line temperature was $30{ }^{\circ} \mathrm{C}$. From the volumetric composition of these gases, volumetric carbon concentrations were calculated. Combining the volumetric carbon concentration with the volumetric gas flow rate, the mass flow of carbon in the gas phase was obtained.

\subsubsection{Liquid composition}

The carbon concentration of the feed stream (mg.g $\left.{ }^{-1}\right)$ in the first run was calculated from the applied concentration (0.78wt\%) of organic feed (i.e., cellulose/lignin/acetic acid in water) and the elemental composition of the recycled effluent. In the case of recirculation, the carbon concentration of the feed stream $\left(\mathrm{mg}^{-\mathrm{g}^{-1}}\right)$ increased with the measured total organic carbon concentration (TOC) of the effluent:

$C_{C, \text { feed }}=C_{C, \text { fresh }}+C_{C, \text { effl }}$.

The total organic carbon concentration within the liquid effluent was measured using a TOC analyzer (TOC-5000 Shimadzu). After dilution of an effluent sample with Milli-Q water to obtain a TOC concentration within the instrument's determination range (0-100 $\mathrm{mg} / \mathrm{L})$, the liquid sample was introduced into the analyzer and measured in triplicate.

The concentration of carbon (mg.g $\mathrm{g}^{-1}$ ) within the reaction mixture (feed stream and oxidizer stream) constituted the actual stream subjected to SCWO in the reactor tube (Fig. S1). The mixture's carbon concentration was calculated from the carbon concentration of the feed and the flow rate of the feed stream and oxidizer stream (Section 2.2): 


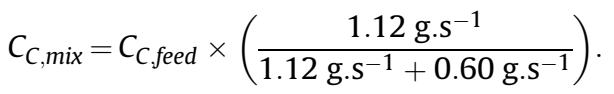

\subsubsection{Carbon balance}

The carbon balance closure $(\mathrm{CB}, \%)$ was calculated by the weight of the different phases as:

$C B(\%)=\frac{C_{C, \text { gas }} \times w_{\text {mix }}+C_{C, \text { effl }} \times w_{\text {effl }}}{C_{C, \text { mix }} \times w_{\text {mix }}} \times 100$.

where, $C_{C, \text { gas }}\left(\mathrm{mg} \mathrm{g}^{-1}\right)$ represents the concentration of carbon in the gaseous products per gram of treated reaction mixture. The carbon concentration in the gaseous products was calculated from the volumetric composition, the volumetric flow rates of evolved gases and the mass flow rate of the treated reaction mixture. $C_{C, \text { effl }}$ (mg. $\mathrm{g}^{-1}$ ) denotes the carbon concentration in the liquid effluent, while $C_{C \text {,mix }}$ represents the concentration of carbon $\left(\mathrm{mg}^{-g^{-1}}\right)$ in the reaction mixture. The $w_{i}$ represents the weight of treated reaction mixture and liquid effluent, respectively.

\subsubsection{Oxidation efficiency}

The oxidation efficiency (OE, \%) was calculated from the carbon concentration of the evolved gases from per gram of reaction mixture (mg. $\mathrm{g}^{-1}$ ) and the carbon concentration of the treated reaction mixture:

$O E(\%)=\frac{C_{C, \text { gas }}}{C_{C, \text { mix }}} \times 100$.

\subsubsection{Cumulative oxidation efficiency}

The cumulative oxidation efficiency ( $\mathrm{COE}, \%)$ was calculated to infer the overall oxidation efficiency of the organics over multiple SCWO runs upon recirculation. The cumulative oxidation efficiency allowed an assessment of the hypothesis put forth in the Introduction.

Fig. 2 b illustrates how the evolved gases and residuals in the effluent were composed, being one fraction from the freshly injected feed and other fractions from the consecutive incomplete oxidation residual carbon from previously injected feeds. The partitioning of carbon in the gas phase and aqueous residuals was done, like in Fig. 2 b, assuming that fresh feed and dissolved residuals in the effluent from previous runs decompose independently.

The cumulative oxidation efficiency of organic carbon injected in the first run $(n=1)$ after $y$ subsequent SCWO runs, $C O E_{1, y}(\%)$, was calculated for each feedstock as follows:

$$
\begin{aligned}
\mathrm{COE}_{1, y}(\%) & =\left[O E_{1,1}+\left(100 \%-O E_{1,1}\right) \times O E_{1,2}+\ldots\right. \\
& \left.+\left(100 \%-O E_{1, y-1}\right) \times O E_{1, y}\right] \times 100 .
\end{aligned}
$$

The $O E_{1,1}(\%)$ represents the oxidation efficiency of fresh feed for a single pass at studied mild SCWO conditions, while $O E_{1, x}$ $(1<x<y)$ expresses the oxidation efficiency of residual carbon stemming from the firstly injected feed during the $x^{\text {th }}$ run.

Values for the $O E_{1, x}$ were obtained by dividing the increase of carbon in the gas from run $x-1$ to $x$ (e.g., Gas Ga $_{1-3}$ in Fig. $2 \mathrm{~b}$ ) with the carbon concentration of the mixture's fraction attributed to residual organic carbon from run 1 (e.g., Residual ${ }_{1-2}$ in Fig. 2b). All the data can be found in Table 1.

\section{Results and discussion}

Table 1 presents the results for five SCWO runs (i.e., one initial run and four recirculation runs) of the three applied organics feedstocks. Upon recirculation, the "feed stream" in Fig. 2 a contained carbon from freshly fed cellulose or lignin or acetic acid, and carbon from the intermediates. Table 1 presents both the carbon concentration in the feed stream, as well as in the reaction mixture (i.e., after mixing the "feed stream" with "oxidizer stream", Fig. 2a). Outgoing streams from SCWO are the gaseous products (Fig. 3) and the aqueous effluent (Table 1). The gas composition of detected gaseous species is presented in Fig. 3. The volume of quantified gases, being $\mathrm{H}_{2}, \mathrm{O}_{2}, \mathrm{CO}, \mathrm{CO}_{2}$ and $\mathrm{C}_{2} \mathrm{H}_{4}$ in the total gaseous effluent volume was $96.24 \pm 0.98$ vol\%, indicating a good balance on volume basis for the detected gases. The main gaseous species evolved, were $\mathrm{O}_{2}, \mathrm{CO}_{2}, \mathrm{CO}$ and $\mathrm{H}_{2}$. The average volume contribution of ethene was on average only $0.04 \%$. Specific trends of the volumetric composition of evolved gases throughout the consecutive runs is discussed in Section 3.2.

\subsection{Oxidation for a single-pass SCWO}

A single-pass SCWO of cellulose, lignin and acetic acid at $380{ }^{\circ} \mathrm{C}$ and $25 \mathrm{MPa}$, with an OER of 2.0 and residence time of $26 \mathrm{~s}$, reached moderate oxidation efficiencies of $63.9 \%, 45.3 \%$ and $28.3 \%$, respectively (Table 1).

Literature data on SCWO of cellulose is scarce, but a $\mathrm{CO}_{2}$ yield (i.e., oxidation efficiency) was reported of $\mathrm{ca}$. 80\% for SCWO operated at a residence time of ca. $20 \mathrm{~s}, 382{ }^{\circ} \mathrm{C}$ and an OER as high as 10.0 (Pisharody et al., 1996).

Lignin subjected to SCWO at a temperature of $504{ }^{\circ} \mathrm{C}$ and a residence time of $10.4 \mathrm{~s}$ resulted in the conversion efficiency of $72.1 \%$. At a residence time of $26.9 \mathrm{~s}$, a conversion efficiency of $90.6 \%$ was achieved (30.5 MPa) (Drews et al., 2000; Fedyaeva et al., 2019).

Zhang et al. achieved an acetic acid removal between 10 and 15\% during SCWO operated at $400{ }^{\circ} \mathrm{C}$ and at OERs between 1.24 and 4.29 with a residence time of $47 \mathrm{~s}$ (Zhang et al., 2013). This efficiency is less than that observed in this study, which probably results from the lower concentration we conducted. However, upon an increase of the operating temperature to $500^{\circ} \mathrm{C}$, under the same OERs, and a residence time of $27 \mathrm{~s}$, acetic acid degradation increased to ca 70-90\% (depending on the OER) (Zhang et al., 2013). Takahashi et al., on the other hand reached acetic acid conversions between 20 and $30 \%$ for operation at $450{ }^{\circ} \mathrm{C}$ and at residence times ranging from 20 to $60 \mathrm{~s}$ and an OER as high as 10 (Takahashi et al., 2012).

In general, the single-pass oxidation efficiencies obtained of the herein presented study are smaller than those reported in the aforementioned literature. Obviously, these studies aimed to maximize the oxidation efficiencies, often by increasing the temperature and/or OER, as was stated in the Introduction. Having operated SCWO in this study at mild conditions, the herein moderate single-pass oxidation efficiencies were anticipated. Overall, it is however confirmed that cellulose is the most prone to SCWO, followed by lignin and acetic acid, which was the most difficult to oxidize under current conditions (Mizuno et al., 2000; Cabeza et al., 2011; Zhang et al., 2013). This sequence of oxidation susceptibility is related to the structure of the feed and especially stability of induced radicals. Indeed, acetic acid can react with a hydroxyl radical (from peroxide) to form an 0 -centered acetic acid radical, which is stabilized by the $\pi$-bonds of the carboxyl group. Similarly, lignin as the second-most difficult compound to oxidize, can form semi-stabilized phenoxyl radials also due to stabilization by $\pi$ bonds in the aryl moiety (Wang et al., 2020).

To confirm the hypothesis from the Introduction, the oxidation 
Table 1

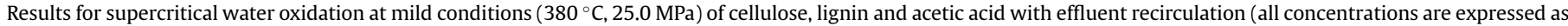

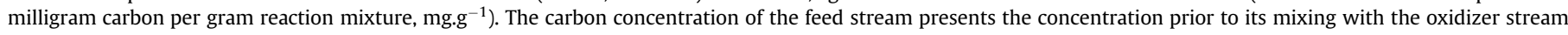

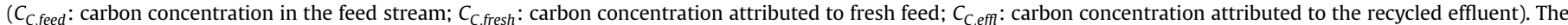

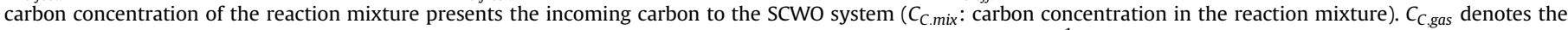

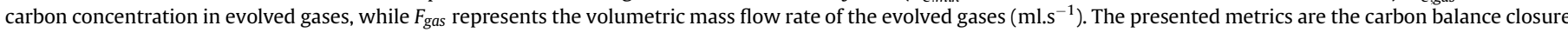

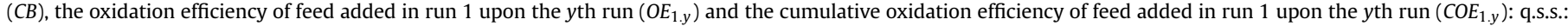
quasi-steady state, being complete oxidation.

\begin{tabular}{|c|c|c|c|c|c|c|c|c|c|c|c|c|c|}
\hline \multirow[t]{2}{*}{ Feed } & \multirow[t]{2}{*}{ Run } & \multicolumn{3}{|c|}{ Carbon in feed stream } & \multicolumn{3}{|c|}{ Incoming carbon (reaction mixture) } & \multicolumn{3}{|c|}{ Outgoing carbon } & \multicolumn{3}{|l|}{ Metrics } \\
\hline & & $C_{C \text {.feed }}$ & $C_{C, f r e s h}$ & $C_{\text {C.effl }}$ & $C_{\text {C.mix }}$ & from $C_{C, f r e s h}$ & from $C_{C . e f f l}$ & $C_{C, \text { gas }}$ & $F_{\text {gas }}$ & $C_{\text {C.effl }}$ & $C B(\%)$ & $O E_{1 . y}(\%)$ & $\operatorname{COE}_{1 . y}(\%)$ \\
\hline \multirow[t]{5}{*}{ Cellulose } & 1 & 3445 & 3445 & 0.00 & 2242 & 2242 & 0 & $1432 \pm 35$ & 14.39 & $798 \pm 11$ & $99.5 \%$ & $63.9 \%$ & $63.9 \%$ \\
\hline & 2 & 4243 & 3445 & $798 \pm 11$ & 2761 & 2242 & 527 & $1699 \pm 38$ & 14.39 & $1050 \pm 9$ & $99.6 \%$ & $51.4 \%$ & $82.4 \%$ \\
\hline & 3 & 4495 & 3445 & $1050 \pm 9$ & 2925 & 2242 & 696 & $1862 \pm 20$ & 14.72 & $1035 \pm 4$ & $99.0 \%$ & $99.4 \%$ & $99.9 \%$ \\
\hline & 4 & 4480 & 3445 & $1035 \pm 4$ & 2915 & 2242 & 700 & $1907 \pm 20$ & 14.39 & $1025 \pm 16$ & $100.6 \%$ & q.s.s. & q.s.s. \\
\hline & 5 & 4470 & 3445 & $1025 \pm 16$ & 2909 & 2242 & 674 & $1910 \pm 16$ & 13.92 & $1056 \pm 25$ & $102.0 \%$ & q.s.s. & q.s.s. \\
\hline \multirow[t]{5}{*}{ Lignin } & 1 & 5357 & 5357 & 0.00 & 3486 & 3486 & 0 & $1579 \pm 29$ & 26.10 & $1902 \pm 16$ & $99.9 \%$ & $45.3 \%$ & $45.3 \%$ \\
\hline & 2 & 7259 & 5357 & $1902 \pm 16$ & 4724 & 3486 & 1241 & $2236 \pm 6$ & 26.03 & $2480 \pm 23$ & $99.8 \%$ & $53.1 \%$ & $74.3 \%$ \\
\hline & 3 & 7837 & 5357 & $2480 \pm 23$ & 5100 & 3486 & 1621 & $2377 \pm 36$ & 25.99 & $2703 \pm 38$ & $99.6 \%$ & $37.5 \%$ & $84.0 \%$ \\
\hline & 4 & 8060 & 5357 & $2703 \pm 38$ & 5245 & 3486 & 1776 & $2495 \pm 50$ & 25.72 & $2799 \pm 26$ & $100.9 \%$ & $81.3 \%$ & $97.0 \%$ \\
\hline & 5 & 8156 & 5357 & $2799 \pm 26$ & 5307 & 3486 & 1801 & $2452 \pm 57$ & 25.72 & $2856 \pm 57$ & $100.0 \%$ & q.s.s. & q.s.s. \\
\hline \multirow[t]{5}{*}{ Acetic acid } & 1 & 3119 & 3119 & 0.00 & 2030 & 2030 & 0 & $575 \pm 18$ & 11.72 & $1424 \pm 7$ & $98.5 \%$ & $28.3 \%$ & $28.3 \%$ \\
\hline & 2 & 4543 & 3119 & $1424 \pm 7$ & 2957 & 2030 & 947 & $748 \pm 13$ & 12.05 & $2101 \pm 15$ & $96.4 \%$ & $18.7 \%$ & $41.7 \%$ \\
\hline & 3 & 5220 & 3119 & $2101 \pm 15$ & 3397 & 2030 & 1450 & $912 \pm 13$ & 12.85 & $2612 \pm 29$ & $103.7 \%$ & $37.2 \%$ & $63.4 \%$ \\
\hline & 4 & 5731 & 3119 & $2612 \pm 29$ & 3730 & 2030 & 1671 & $1121 \pm 16$ & 12.79 & $2613 \pm 33$ & $100.1 \%$ & $62.9 \%$ & $86.4 \%$ \\
\hline & 5 & 5732 & 3119 & $2613 \pm 33$ & 3730 & 2030 & 1679 & $1125 \pm 24$ & 12.72 & $2589 \pm 46$ & $99.6 \%$ & q.s.s. & q.s.s. \\
\hline
\end{tabular}

efficiencies of the injected organic carbon from cellulose, lignin and acetic acid should go from $63.9 \% .45 .3 \%$ and $28.3 \%$ respectively to ca. $100 \%$ after $n$ runs (or $n-1$ times recirculation of the effluent).

\subsection{Effect of recirculation}

Table 1 presents the experimental data from five SCWO experiments with 4 recirculation runs for all three feedstocks. The carbon in the reaction mixture entering the SCWO reactor in the first run only stems from freshly injected feed (e.g., $2242 \mathrm{mg} \mathrm{g}^{-1}$ for cellulose-carbon), while incoming carbon in the reaction mixture for subsequent runs stemmed from both freshly injected feed and the recycled part of the liquid effluent from the previous run.

Direct evidence for consecutive oxidation of residuals upon effluent recirculation is reflected in the carbon concentration of the reaction mixture (incoming) and the carbon concentration in outgoing gas and liquid effluent over the course of multiple runs (Table 1). If recirculation would not facilitate consecutive oxidation of residuals within the effluent, an ever-increasing build-up of the carbon would be expected in the gas and liquid effluent. SCWO efficiency at present mild conditions was only 63.9\%. $45.3 \%$ and $28.3 \%$ for cellulose, lignin and acetic acid, respectively. The fresh injection of feed would give rise to the accumulation of carbon in both gas and liquid effluent. However, a quasi-steady carbon concentration had been reached for both the gas and liquid effluent after a number of runs. Insignificant changes of the carbon concentration in the liquid effluent and evolved gases are indicated in Table 1 with q.s.s., meaning quasi-steady state.

A common feature is that the quasi-steady carbon concentration for the liquid effluent was reached one run before that of the gas effluent. The steady state concentration in the liquid effluent for cellulose was $1035 \mathrm{mg} \mathrm{g}^{-1}$ at run 3, because this value differed insignificantly from the previous and next value. Similarly the steady state concentration in the gas phase was $1907 \mathrm{mg} \cdot \mathrm{g}^{-1}$ at run 4. This earlier transition from the build-up to a quasi-steady carbon concentration in the effluent, compared to carbon in the gas phase, falls within expectations. In the case of cellulose (Table 1), effluent from run 2 was recycled to run 3 , then almost entirely oxidized into gases, leading to negligible carbon build-up in the aqueous effluent while building up carbon in the gas phase.
Fig. 3, showing the volumetric composition of evolved gases, also indicates the establishment of a steady-state in the gas effluent. While the flow rate of evolved gases $F_{\text {gas }}$ merely changed upon recirculation (Table 1 ), changes in the gas composition were apparent. For all tested feeds, the specific volume of evolved oxygen gas decreased, while carbon dioxide in the evolved gases increased, before both gases settled to a stable gas composition after a specific number of runs. For cellulose and lignin, a stable gas composition was observed from the 3rd run forward, while for acetic acid, a stable gas composition was apparent from the 4 th run.

\subsection{Cumulative oxidation efficiency}

\subsubsection{Cellulose}

The cumulative oxidation efficiency of organic carbon, stemming from cellulose, lignin and acetic acid, was calculated throughout the sequence of SCWO runs (data in Table 1). The calculation procedure could be found in the supplementary materials. The COEs of cellulose showed that oxidation of carbon went from $63.9 \%$ to $99.9 \%$ after 3 SCWO runs (i.e., 2 recirculation runs). This is visualized in Fig. 4. At SCWO run 2, carbon was present in the aqueous effluent due to (i) incomplete oxidation of carbon from the first cellulose injection (COE of $82.4 \%$, full line) and (ii) the incomplete oxidation of the second injection of cellulose-C (COE of $63.9 \%$, dashed line). As a result, the carbon in the effluent built up during the first three runs. At the 3rd run, a quasi-steady state was reached where cellulose-carbon from the first run had been completely oxidized. After the 4th run, all the cellulose-carbon from the second run would be virtually oxidized completely. Afterwards, the incoming carbon and outgoing carbon achieved a balance. Any fresh feedstock could be gradually oxidized to completion.

\subsubsection{Lignin}

Results for lignin were similar to those for cellulose (Table 1). Carbon in the gas and effluent rapidly build up, followed by a quasisteady situation. The carbon build-up in the effluent transitions to a steady mass flow from run 3 to run 4; delayed by one run compared to cellulose. This observation indicates an increased recalcitrance of lignin compared to cellulose, which is consistent with findings in 

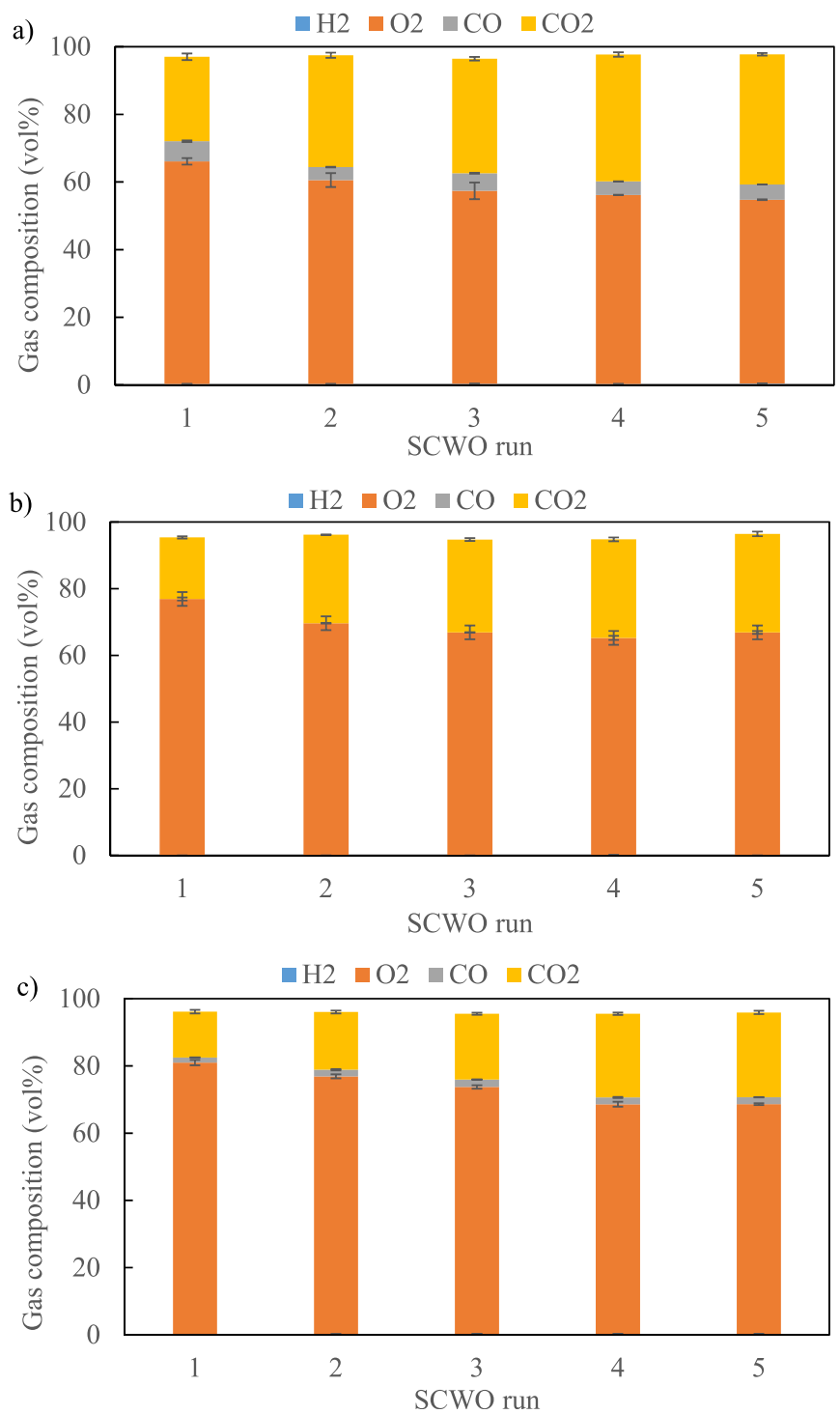

Fig. 3. Change of volumetric composition of evolved gases during SCWO of cellulose (a), lignin (b) and acetic acid (c) with effluent recirculation.

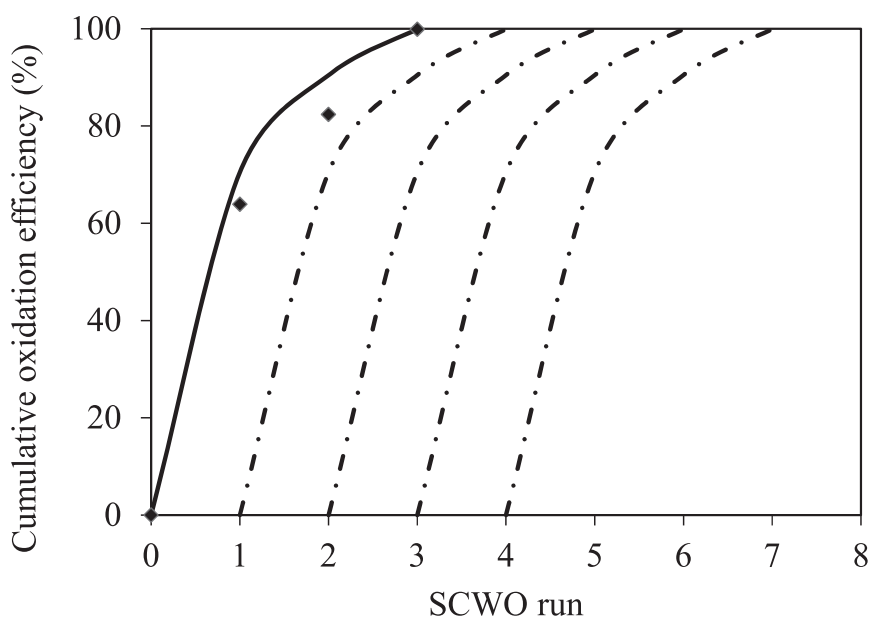

Fig. 4. Cumulative oxidation efficiency of cellulose added in the first run ( $\left.\mathrm{COE}_{1 . x}, \%\right)$ during 5 consecutive SCWO runs (solid line). The dashed lines indicate the expected COEs of cellulose added in subsequent runs $(x>1)$. the literature (Balakrishnan et al., 2011). The fact that a quasisteady situation had been reached, indicates an increased conversion from $45.3 \%$ without recirculation, to $97.0 \%$ with effluent recirculation of minimum 3 times, then to fully oxidation.

\subsubsection{Acetic acid}

Even for acetic acid, the most refractory among the tested organics, an increasing cumulative oxidation of initial feed was observed (Table 1). Like cellulose and lignin, carbon in the effluent initially increased dramatically, after which it increased/decreased only modestly. From run 3 to 4 , carbon in the effluent transients from a build-up to a steady concentration situation. This transition from build-up to steady situation lags one other run with lignin (i.e., from run four to five) due to increased recalcitrance. Yet, it cumulatively oxidizes extensively (86.4\%) within 4 runs, and then assumed completely at the 5th run. We conclude that recirculation thus enabled extensive oxidation of acetic acid as well.

It is presumed that the oxidation mechanisms for the different feedstocks were not altered by effluent recirculation. Instead, the prolonged residence time was held accountable for the increasing COEs of the feedstocks. Nevertheless, the extent by which the COE increases would depend on the susceptibility of feedstock to oxidation. Indeed, acetic acid is known as a refractory compound and therefore required the most number of runs (Miller et al., 2015), while cellulose is the easiest to oxidize and required the least number of runs.

\subsection{Implications, limitations and future perspectives}

\subsubsection{From principle to concept}

As stated in section 2.3, there is one concern in our principle that the liquid volume of effluent would build up every run due to the oxidizer being an aqueous solution of hydrogen peroxide, wet feedstock, and the formation of chemical water. For this work, the excess effluent was not removed, resulting in an increasing aqueous effluent, further an ever-increasing overall reaction time. For the herein presented proof-of-principle, this has no consequence. However, to transient from a proof-of-principle to a proof-ofconcept, the removal of the excess effluent becomes an inevitable issue.

Reverse osmosis (RO) is a suitable technology to concentrate dissolved organic carbon in the liquid effluent and to remove excess clean water out of the system prior to recirculation. By doing so, SCWO with effluent recirculation and reverse osmosis would also enable the production of a carbon-free effluent, while maintaining the other advantages of high oxidizing capacity. The comparison of high carbon oxidizing capacity among: (i) a single-pass SCWO process, (ii) SCWO as performed in this work and (iii) SCWO with integrated reverse osmosis is made in Section 3.4.2.

The typical elevated costs that come with reverse osmosis, being liquid pressurization, would not be an issue in this case, as SCWO is an inherent high-pressure system. Therefore, the existing outlet pressure of the effluent, with a partial reduction thereof, can be used to drive the reversed osmosis. This concept is illustrated in Fig. S2 (or Table 2: case 3).

Working with reverse osmosis in its turn poses additional challenges. Waste streams with significant quantities of (dissolved) salts (e.g., Cl-. P- and S-based ones) will be retained within the SCWO system with reverse osmosis, once introduced. In a set-up, such as presented in Fig. S2, a risk exists that soluble salts precipitate in supercritical conditions and cause plugging. Salts can also accelerate corrosion. Consequently, the removal of these salts from the recirculating system should also be considered. An elegant solution would be to cease fresh input of waste or feedstock, if the salt concentration is higher than a certain threshold, run another $n$ 
Table 2

Features of a single-pass process, the herein process, and a hypothetical process representing the best criterion.

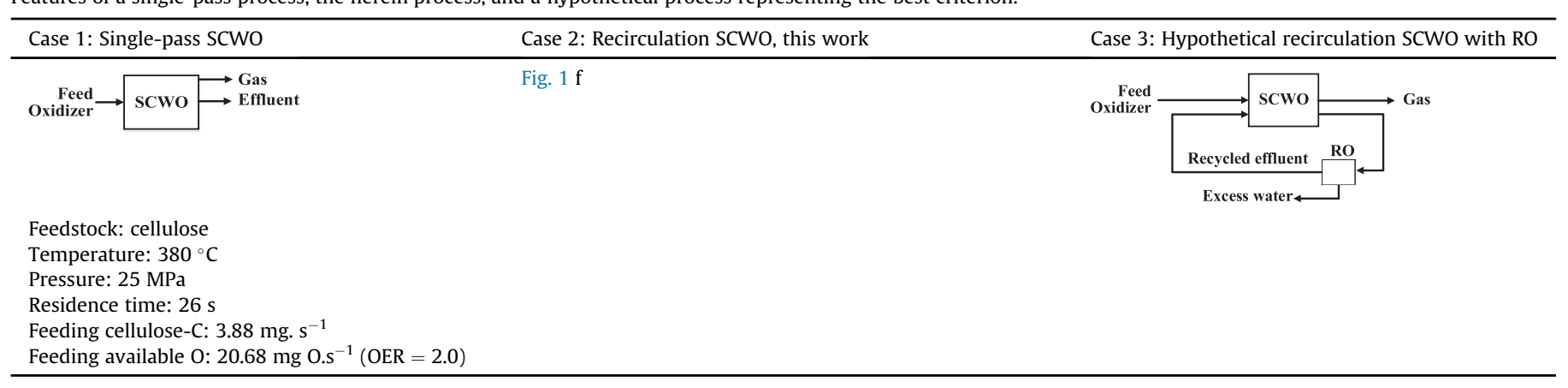

runs until present organics are oxidized completely and discard the carbon-free but salt-laden reactor volume. Operation can then be resumed with fresh water. Alternative salt removal strategies applied in conventional SCWO set-ups. e.g., the MODAR vessel reactor (Huang et al., 1992), could be applied as well.

\subsubsection{Oxidation capacity and oxidizer consumption}

The herein reported SCWO principle was compared, in terms of oxidation capacity and oxidizer consumption, to a single-pass SCWO process and a SCWO process with integrated reverse osmosis (hypothetical calculations). All processes were assumed continuous. The principal features and assumptions for these three cases are summarized in Table 2.

In case 1, only a single-pass SCWO experiment with cellulose was considered. According to the experimental results from Table 1 , the oxidation efficiency was $63.9 \%$. In case 2 , experimental data from SCWO with aqueous effluent recirculation was used. The observed effluent gas flow and its carbon concentrations were translated into a mass flow of gas- $\mathrm{C}\left(\mathrm{mg}\right.$. $\left.\mathrm{s}^{-1}\right)$. Case 3 thus presents simulated results that would be expected if a RO was installed, and the organic rejection of the RO was ideally assumed to be $100 \%$. The calculation of outgoing gas- $C$ was based on the cumulative oxidation efficiencies (COE). As Eqs. (5) and (6) took dilution into account, the numbers for $\mathrm{COE}$ are fundamental, dilution-independent and therefore suited to calculate the mass flow of outgoing carbon $\left(\mathrm{mg} . \mathrm{s}^{-1}\right)$. Fig. 5 compares the performance of three cases in Table 2. The data to compose Fig. 5 could be found in the supplementary materials (Tables S1 and S2).

Fig. 5 a illustrates that the cumulatively evolved gas- $C$ in this work is far beyond the single-pass process, resulting from the additional oxidation of undecomposed intermediates through recirculation. Besides, the hypothetical process, being the best results obtained from the recirculation process, could convert almost all influx carbon to gas phase.

Fig. $5 \mathrm{~b}$ presents the ratio of evolved gas-C $\left(\mathrm{mg}^{-\mathrm{s}^{-1}}\right)$ over cellulose-C influx (mg.s $\mathrm{s}^{-1}$ ) for all three cases in Table 2 and indicates the oxidation capacity. For the single-pass experiments in case 1, this ratio remained constant over time, being 0.639 (the single-pass oxidation efficiency). For case 2 (this work), the ratio of evolved gas-C over fed cellulose-C (mg.s $\left.{ }^{-1}\right)$ gradually increased because of consecutive oxidation from recycling and plateaued at a value of ca. 0.8 , which was due to dilution of intermediates in the aqueous effluent by fresh oxidizer, as stated in section 2.3. However, for case 3 , the gas- $C$ outflux over the cellulose- $C$ influx ratio almost reached $100 \%$. While effluent recirculation without excess water removal already achieved high oxidation capacities, removal of excess water through RO would result in a near-100\% oxidation capacity at mild conditions with a concise set-up.

Fig. $5 \mathrm{~b}$ also learns that the ratio of added oxygen over the evolution of gas-C is less in the recirculation work. SCWO with effluent recirculation consumes less oxygen, relative to the quantity of evolved gas- $\mathrm{C}$, compared to the hypothetical process, indicating a higher oxidizer use efficiency. This coincides with the fact that oxygen gas yield in gas effluent drops with recirculation runs (Fig. 3). In summary, the principle of effluent recirculation for SCWO would enable a high throughput of organics, with less use of oxygen, compared to a conventional SCWO, operated according to Table 2.

\subsubsection{Feedstock independence and reactor configuration}

From Table 1 and Fig. 5, it was clear that SCWO at mild conditions was unable to completely oxidize the tested organics in one run. As stated in the introduction, complete oxidation might be reached under harsher conditions, which can compromise longterm application (corrosion at high temperature and ORE in especial, reactor vulnerability for larger reactors). Different organic feeds also resulted in different single-pass oxidation efficiencies (Table 1). Nevertheless, SCWO with effluent recirculation could be considered more versatile. Indeed, no tailored conditions need to be sought for optimal/complete oxidation. Instead, mild SCWO with effluent recirculation resulted in a steady-state concentration of carbon in the effluent (being around 1030, 2800 and $2600 \mathrm{mg} \mathrm{L}^{-1}$ for cellulose, lignin and acetic acid, respectively) within a specific number of recirculation runs (being 3, 4 and 4 for cellulose, lignin and acetic acid, respectively), which is the principal condition for continuous operation (i.e., oxidation). For waste management strategies, the recirculation run is of specific importance, as various waste streams to be treated might be variable or even undefined.

The principle to recycle effluent is capable of enhancing the oxidation efficiency and indeed suffers some barriers, such as more complex reactor design. Yet, a more versatile and smaller reactor design for different feedstocks at mild conditions could work as a sort of compensation for its complex nature. Additionally, the complex section works at a safe pressure range. Compared with a conventional SCWO process, the proposed process loses its capacity to a small extent yet works at a much milder temperature, lower oxidizer load and shorter or smaller reactor design. The working reaction conditions of the proposed process would allow a less corrosive environment in principle. The proposed principle of this work is to present a novel way to improve SCWO process and give new clues to the development of SCWO. Hypothetically, an easytransportable SCWO system could be developed to handle emergency.

\section{Conclusion}

A proof of principle for mild SCWO is put forth in this work, in which effluent from one SCWO run was recycled. Three tested 
a)

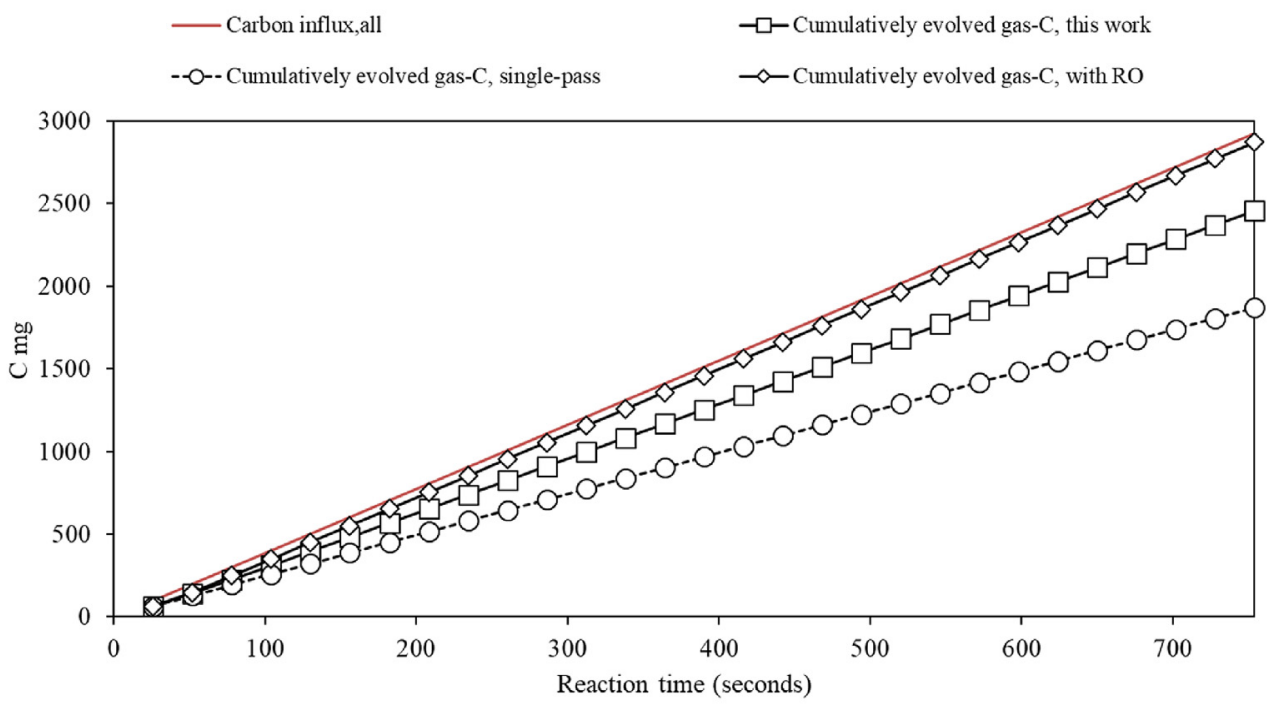

b)

$$
\begin{array}{lll}
-0-\text { gas-C / cellulose-C, single-pass } & -\square-\text { gas-C / cellulose-C, this work } & -\prec \text { gas-C / cellulose-C, with RO } \\
--0--O \text { influx / gas-C, single-pass } & -\square-\text {-O influx / gas-C, this work } & -\diamond--\mathrm{O} \text { influx / gas-C, with RO }
\end{array}
$$

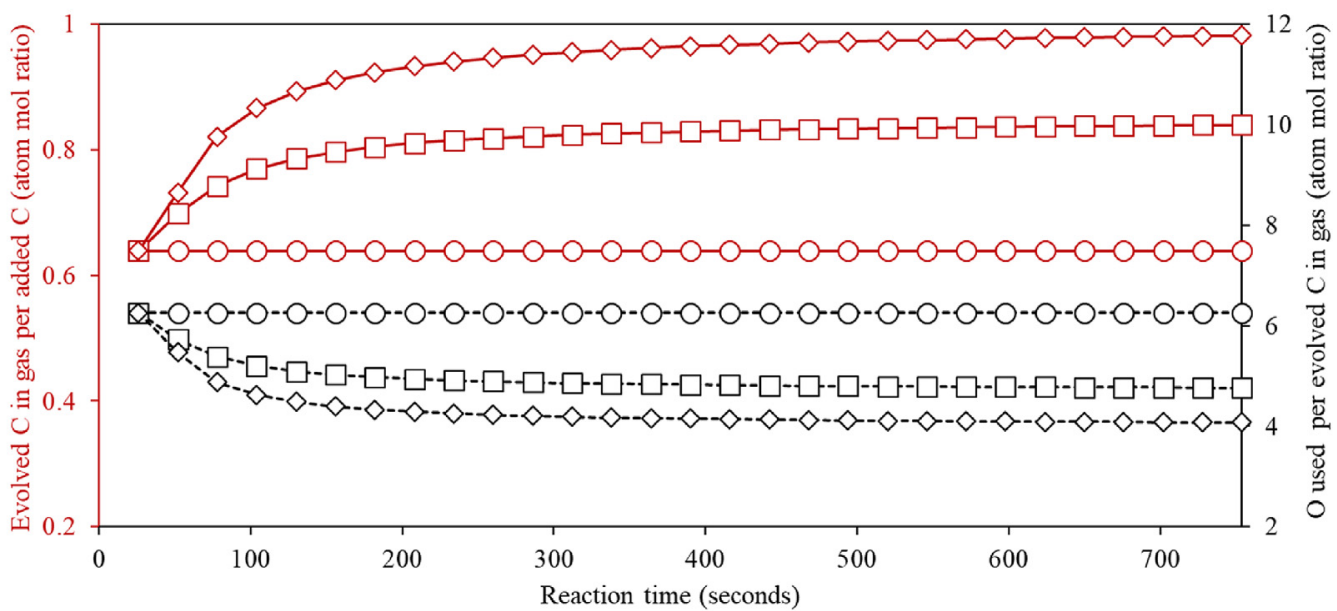

Fig. 5. Oxidation efficiency and oxidizer use efficiency comparison of mild SCWO of cellulose, using three different processes.

model compounds all demonstrated consecutive increasing oxidation to completion after $n$ runs, being $n=4$ for cellulose from $63.9 \%(n=1), n=5$ for lignin from $45.3 \%(n=1)$, and $n=5$ for acetic acid from $28.3 \%(n=1)$. Compared to a conventional principle for SCWO, the proposed one enables a higher oxidation ability with less use of oxygen per evolved gas-C. Moreover, a smaller reactor working at milder conditions is possible. Hence, a concise and less vulnerable reactor could handle different types of feedstock without tailored optimized parameters.

\section{CRediT authorship contribution statement}

Dongdong Zhang: Conceptualization, Methodology, Software, Investigation, Data curation, Formal analysis, Writing - original draft, Writing - review \& editing. Stef Ghysels: Data curation, Writing - original draft, Writing - review \& editing. Frederik Ronsse: Writing - review \& editing, Supervision, Project administration, Funding acquisition.

\section{Acknowledgments}

This work was supported by the China Scholarship Council (CSC), Special Research Fund (BOF) in Ghent University, and Chengdu national agricultural science and technology center (No. NASC2019TI12).

\section{Appendix A. Supplementary data}

Supplementary data to this article can be found online at https://doi.org/10.1016/j.chemosphere.2020.126213. 


\section{Nomenclature}

\begin{tabular}{|c|c|}
\hline \multicolumn{2}{|c|}{ Abbreviations } \\
\hline $\mathrm{CB}$ & Carbon balance, \% \\
\hline$C_{\text {C.effl }}$ & $\begin{array}{l}\text { carbon concentration attributed to the recycled effluent } \\
\text { per gram reaction mixture, } \mathrm{mg} \mathrm{g}^{-1}\end{array}$ \\
\hline$C_{C . f e e d}$ & $\begin{array}{l}\text { carbon concentration in the feed stream per gram } \\
\text { reaction mixture, } \mathrm{mg} \mathrm{g}^{-1}\end{array}$ \\
\hline$C_{C, \text { fresh }}$ & $\begin{array}{l}\text { carbon concentration attributed to fresh feed per gram } \\
\text { reaction mixture, } \mathrm{mg} \mathrm{g}^{-1}\end{array}$ \\
\hline$C_{C, \text { gas }}$ & $\begin{array}{l}\text { carbon concentration in evolved gases per gram } \\
\text { reaction mixture, } \mathrm{mg} \mathrm{g}^{-1}\end{array}$ \\
\hline$C_{\text {C.mix }}$ & $\begin{array}{l}\text { carbon concentration in the reaction mixture per gram } \\
\text { reaction mixture, } \mathrm{mg} \mathrm{g}^{-1}\end{array}$ \\
\hline $\mathrm{COE}$ & Cumulative oxidation efficiency, \% \\
\hline $\mathrm{COE}_{1 . \mathrm{y}}$ & $\begin{array}{l}\text { the cumulative oxidation efficiency of feed added in run } \\
1 \text { upon the } y \text { th run, \% }\end{array}$ \\
\hline COD & Chemical oxygen demand, $\mathrm{mg} \cdot \mathrm{L}^{-1}$ \\
\hline$F_{M}$ & Flow rate of the mixture, $\mathrm{kg} \cdot \mathrm{s}^{-1}$ \\
\hline$F_{\text {gas }}$ & Volumetric mass flow rate of the evolved gases, $\mathrm{ml} \mathrm{s}^{-1}$ \\
\hline OER & Oxidant equivalence ratio \\
\hline $\mathrm{OE}$ & Oxidation efficiency, \% \\
\hline$O E_{1 . y}$ & $\begin{array}{l}\text { Oxidation efficiency of feed added in run } 1 \text { upon the } y \text { th } \\
\text { run, } \%\end{array}$ \\
\hline q.S.S & quasi-steady state \\
\hline SCWO & Supercritical water oxidation \\
\hline TOC & Total organic carbon, $\mathrm{mg} \mathrm{g}^{-1}$ \\
\hline$V_{R}$ & reactor volume, L \\
\hline Wi & Weight of portion $i, \mathrm{~g}$ \\
\hline
\end{tabular}

\section{Greek letters}

$\rho_{M} \quad$ Density of the mixture at atmospheric temperature and pressure, $\left(\mathrm{kg} \cdot \mathrm{L}^{-1}\right)$

$\rho_{\mathrm{R}(\mathrm{P}, \mathrm{T})} \quad$ Density of the mixture at working temperature and pressure, $\left(\mathrm{kg} \cdot \mathrm{L}^{-1}\right)$

\section{Subscripts \\ C,effl \\ C.feed \\ C,gas \\ C,mix \\ Carbon attributed to the aqueous effluent \\ Carbon attributed to the feedstock \\ Carbon attributed to the gas products \\ Carbon attributed to the reaction mixture}

\section{References}

Al-Duri, B., Alsoqyani, F., 2017. Supercritical water oxidation (SCWO) for the removal of $\mathrm{N}$ - containing heterocyclic hydrocarbon wastes; Part II: system kinetics. J. Supercrit. Fluids 128, 412-418.

Al-Duri, B., Alsoqyani, F., Kings, I., 2015. Supercritical water oxidation for the destruction of hazardous waste: better than incineration. Philos. Trans. R. Soc., A 373, 9.

Albrecht, T., 2006. Conversion of Lignocellulosic Materials and Model Compounds in Sub- and Supercritical Water.

Angeles-Hernández, M.J., Leeke, G.A., Santos, R.C.D., 2009. Catalytic supercritical water oxidation for the destruction of quinoline over $\mathrm{MnO} 2 / \mathrm{CuO}$ mixed catalyst. Ind. Eng. Chem. Res. 48, 1208-1214.

Balakrishnan, M., Batra, V.S., Hargreaves, J.S.J., Pulford, I.D., 2011. Waste materials catalytic opportunities: an overview of the application of large scale waste materials as resources for catalytic applications. Green Chem. 13, 16-24.

Bermejo, M.D., Cocero, M.J., 2006. Supercritical water oxidation: a technical review. AIChE J. 52, 3933-3951.

Brunner, G., 2014. Chapter 10 - oxidation in high-temperature and supercritical water. In: Brunner, G. (Ed.), Supercritical Fluid Science and Technology. Elsevier, pp. 525-568.

Cabeza, P., Bermejo, M.D., Jiménez, C., Cocero, M.J., 2011. Experimental study of the supercritical water oxidation of recalcitrant compounds under hydrothermal flames using tubular reactors. Water Res. 45, 2485-2495.

Chen, Z., Wang, G.W., Yin, F.J., Chen, H.Z., Xu, Y.J., 2015. A new system design for supercritical water oxidation. Chem. Eng. J. 269, 343-351.

Cocero, M., Vallelado, D., Torio, R., Alonso, E., Fdez-Polanco, F., 2000. Optimisation of the operation variables of a supercritical water oxidation process. Water Sci.
Technol. 42, 107-113.

Drews, M.J., Barr, M., Williams, M., 2000. A kinetic study of the SCWO of a sulfonated lignin waste stream. Ind. Eng. Chem. Res. 39, 4784-4793.

Fang, Z., 2014. Near-critical and Supercritical Water and Their Applications for Biorefineries. Springer.

Fedyaeva, O.N., Vostrikov, A.A., Shishkin, A.V., Sokol, M.Y., 2019. Transformation of lignin under uniform heating. II. Combustion in a flow of water-oxygen mixture. J. Supercrit. Fluids 148, 24-32.

Gong, Y., Guo, Y., Wang, S., Song, W., 2016. Supercritical water oxidation of Quinazoline: effects of conversion parameters and reaction mechanism. Water Res. $100,116-125$.

Gong, Y.M., Wang, S.Z., Xu, H.D., Guo, Y., Tang, X.Y., 2015. Partial oxidation of landfill leachate in supercritical water: optimization by response surface methodology. Waste Manag. 43, 343-352.

Guo, Y., Wang, S., Gong, Y., Xu, D., Tang, X., Ma, H., 2010. Partial oxidation of municipal sludge with activated carbon catalyst in supercritical water. J. Hazard Mater. 180, 137-144.

Huang, C., Barner, H., Albano, J., Killilea, W., Hong, G., 1992. Method for Supercritical Water Oxidation, p. 17.

Jimenez-Espadafor, F., Portela, J.R., Vadillo, V., Sánchez-Oneto, J., Becerra Villanueva, J.A., Torres García, M., Martínez de la Ossa, E.J., 2011. Supercritical water oxidation of oily wastes at pilot plant: simulation for energy recovery. Ind. Eng. Chem. Res. 50, 775-784.

Jin, F.-M., Kishita, A., Moriya, T., Enomoto, H., 2001. Kinetics of oxidation of food wastes with $\mathrm{H} 2 \mathrm{O} 2$ in supercritical water. J. Supercrit. Fluids 19, 251-262.

Lousteau, C., Ayadi, H., Descorme, C., 2017. Aqueous phase (catalytic) wet air oxidation of ammonia: thermodynamic considerations. Appl. Catal., B 202, $12-20$.

Ma, H., Wang, S., Zhou, L., Gong, Y., Xu, D., Wang, Y., Guo, Y., 2012. Abatement of aniline in supercritical water using oxygen as the oxidant. Ind. Eng. Chem. Res. 51, 9475-9482.

Marrone, P.A., 2013. Supercritical water oxidation-current status of full-scale commercial activity for waste destruction. J. Supercrit. Fluids 79, 283-288.

Matsumura, Y., Nunoura, T., Urase, T., Yamamoto, K., 2000. Supercritical water oxidation of high concentrations of phenol. J. Hazard Mater. 73, 245-254.

Meyer, J.C., Marrone, P.A., Tester, J.W., 1995. Acetic acid oxidation and hydrolysis in supercritical water. AIChE J. 41, 2108-2121.

Miller, A., Espanani, R., Junker, A., Hendry, D., Wilkinson, N., Bollinger, D., AbelleiraPereira, J.M., Deshusses, M.A., Inniss, E., Jacoby, W., 2015. Supercritical water oxidation of a model fecal sludge without the use of a co-fuel. Chemosphere 141, 189-196.

Mizuno, T., Goto, M., Kodama, A., Hirose, T., 2000. Supercritical water oxidation of a model municipal solid waste. Ind. Eng. Chem. Res. 39, 2807-2810.

Mylapilli, S.V.P.R., Sivamohan, N., 2019. Sub and supercritical water oxidation of pharmaceutical wastewater. J. Environ. Chem. Eng. 7, 103165.

Pisharody, S.A., Fisher, J.W., Abraham, M.A., 1996. Supercritical water oxidation of solid particulates. Ind. Eng. Chem. Res. 35, 4471-4478.

Portela, J.R., Nebot, E., de la Ossa, E.M., 2001. Generalized kinetic models for supercritical water oxidation of cutting oil wastes. J. Supercrit. Fluids 21, 135-145.

Qian, L., Wang, S., Ren, M., Wang, S., 2019. Co-oxidation effects and mechanisms between sludge and alcohols (methanol, ethanol and isopropanol) in supercritical water. Chem. Eng. J. 366, 223-234.

Shimoda, E., Fujii, T., Hayashi, R., Oshima, Y., 2016. Kinetic analysis of the mixture effect in supercritical water oxidation of ammonia/methanol. J. Supercrit. Fluids $116,232-238$.

Shin, Y.H., Shin, N.C., Veriansyah, B., Kim, J., Lee, Y.-W., 2009. Supercritical water oxidation of wastewater from acrylonitrile manufacturing plant. J. Hazard Mater. 163, 1142-1147.

Sögüt, O.Ö., Akgün, M., 2009. Removal of C.I. Basic Blue 41 from aqueous solution by supercritical water oxidation in continuous-flow reactor. J. Ind. Eng. Chem. 15, $803-808$.

Takahashi, F., Sun, Z., Fukushi, K., Oshima, Y., Yamamoto, K., 2012. Catalytic oxidation of acetic acid over sodium titanate synthesized hydrothermally in supercritical water. J. Supercrit. Fluids 61, 126-133.

Tan, Y., Shen, Z., Guo, W., Ouyang, C., Jia, J., Jiang, W., Zhou, H., 2014. Temperature sensitivity of organic compound destruction in SCWO process. J. Environ. Sci. (Beijing, China) 26, 512-518.

Wang, S., Guo, Y., Chen, C., Zhang, J., Gong, Y., Wang, Y., 2011. Supercritical water oxidation of landfill leachate. Waste Manag. 31, 2027-2035.

Wang, S., Xu, D., Guo, Y., Tang, X., Wang, Y., Zhang, J., Ma, H., Qian, L., Li, Y., 2020 Oxidative Mechanisms and Kinetics of Organics in Supercritical Water. Supercritical Water Processing Technologies for Environment, Energy and Nanomaterial Applications. Springer Singapore, Singapore, pp. 47-108.

Yang, B., Shen, Z., Cheng, Z., Ji, W., 2017. Total nitrogen removal, products and molecular characteristics of $14 \mathrm{~N}$-containing compounds in supercritical water oxidation. Chemosphere 188, 642-649.

Yang, J., Wang, S., Li, Y., Zhang, Y., Xu, D., 2019. Novel design concept for a commercial-scale plant for supercritical water oxidation of industrial and sewage sludge. J. Environ. Manag. 233, 131-140.

Zhang, D., Clauwaert, P., Luther, A., López Barreiro, D., Prins, W., Brilman, D.W.F. Ronsse, F., 2018. Sub- and supercritical water oxidation of anaerobic fermentation sludge for carbon and nitrogen recovery in a regenerative life support system. Waste Manag. 77, 268-275.

Zhang, D., Luther, A.K., Clauwaert, P., Ciccioli, P., Ronsse, F., 2020. Assessment of carbon recovery from solid organic wastes by supercritical water oxidation for a 
regenerative life support system. Environ. Sci. Pollut. Res.

Zhang, D., Luther, A.K. Clauwaert, P., Ronsse, F., 2019a. Mild temperature hydrothermal oxidation of anaerobic fermentation filtrate for carbon and nitrogen recovery in a regenerative life support system. J. Supercrit. Fluids 145, 39-47. Zhang, J., Wang, S., Guo, Y., Xu, D., Li, X., Tang, X., 2013. Co-oxidation effects of methanol on acetic acid and phenol in supercritical water. Ind. Eng. Chem. Res. 52, 10609-10618.

Zhang, J., Wang, S., Ren, M., Lu, J., Chen, S., Zhang, H., 2019b. Effect mechanism of auxiliary fuel in supercritical water: a review. Ind. Eng. Chem. Res. 58, 1480-1494.

Zou, D., Chi, Y., Dong, J., Fu, C., Wang, F., Ni, M., 2013a. Supercritical water oxidation of tannery sludge: stabilization of chromium and destruction of organics. Chemosphere 93, 1413-1418.

Zou, D., Chi, Y., Fu, C., Dong, J., Wang, F., Ni, M., 2013b. Co-destruction of organic pollutants in municipal solid waste leachate and dioxins in fly ash under supercritical water using H2O2 as oxidant. J. Hazard Mater. 248-249, 177-184. 